\title{
Production and Characterization of DDT Antibodies and Its Application to Enzyme Immunoassay: Relation of Response and Affinity to Coating Ligand
}

\author{
Ji Youn Hong, ${ }^{\dagger \neq}$ Jong-Hyun Kim,,+ Song-Ja Park, ${ }^{+}$Dong-Seok Lho, ${ }^{\dagger}$ and Myung Ja Choi ${ }^{+},{ }^{*}$ \\ ${ }^{\dagger}$ Bioandysis \& Biotransformation Research Center, Korea Institute of Science \& Technologv, Seoul 136-791, Korea \\ ${ }^{\ddagger}$ Department of Chemistry, Seoul Homen's Cniversitv, Seoul 139-774, Korea \\ Recerved June 25, 2003
}

\begin{abstract}
To development an immunodetection method for DDT, 1.1.1-trichloro-2.2-bis(4-chorophenyl)ethane $\left(p, p^{\circ}\right.$ DDT) and its metabolites ( $p, p^{\prime}$-DDA, $p, p^{\circ}$-DDE. $p, p^{\prime}$-DDD). five derivatives of DDT haptens have been synthesised and characterized as coating ligands for antibody evaluation. The appropriate lengths of linkers were introduced to investigate a matching pair of coating ligand and antibody. Among these hapten derivatives. 2.2-bis(4-chlorophenyl)acetic acid (DDA). 5.5-bis(4-chlorophenyl)-5-hydroxtpentanoic acid (DDHP) and 5.5-bis(4-chlorophenyl)-5-chloropentanoic acid (DDCP) were conjugated with key hole limpet hemocyanin $(\mathrm{KLH})$ for its use as an immunogen. The bovine senum albumin (BSA) conjugates of these derivatives were prepared as a coating ligand for monoclonal antibody screening. Fifteen monoclonal antibody clones were screened using these probes. 6.6-Bis(4-chlorophenyl)-6-hydroxy hexanoic acid (DDHH) and 3-[6.6-Bis(4chloropheny'l)-6-hydroxyhexanoylamino]propanoic acid (DDHHAP), in addition to the above hapten derivatives. were conjugated to ovualbumin (OVA) and bovine serum albumin (BSA) for their use as coating ligands to measure the titration level of the antibody and the displacement of free analytes. The indirect competitive ELISA results indicate that the titration level and free analy'te displacement were greatly influenced by the DDT derivatives and carrier proteins used. Three matching pairs of monoclonal antibodies and coating ligands were selected for the DDT immunoassay: antibody clone IA3 and coating ligand DDA-OVA, IAl and DDHHAP-BSA. and IAt and DDHP-OVA.
\end{abstract}

Key Words : DDT. Coating ligand, Antibody characterization

\section{Introduction}

DDT is an organochlorine pesticide widely used in Africa ${ }^{1}$ since the 1940 s to control malaria and typhus. DDT is a broadly toxic compound that is highly stable and insoluble in water. It tends to pass with food fats into the body and to accumulate in fat deposits in animal tissue. It slowly degrades in tissue mainly to 2.2-bis(4-chlorophenyl)acetic acid (DDA). Its two major breakdown products in the environment are 1,1dichloro-2,2-bis(4-chlorophenyl) ethylene (DDE) and 1,1dichloro-2,2-bis(4-chlorophenyl)ethane (DDD) ${ }^{2-5}$ Despite the effectiveness in controlling malaria, the use of DDT was totally banned in developed countries in the 1970 s because of its harmful effects on the reproductive and the nervous systems. ${ }^{6-10}$ DDT and its breakdown products are still found in air, water, and soil samples. Urinary excretion of DDA has been reported as a sensitivity marker of DDT exposure in humans and other mammals. The urinary excretion of DDA for a normal healthy male ranges from 25 to $120 \mathrm{ng} /$ $\mathrm{mL}$ with those reported earlier. ${ }^{11}$ Air samples in the United States have shown levels of DDT ranging from 0.00001 to $1.56 \mathrm{pg} / \mathrm{mL}^{12}$ In the United States in the early $1970 \mathrm{~s}$, DDT and DDE were reported in surface waters at levels of $1 \mathrm{pg}$. $\mathrm{mL}$ and in soil, ranging from 0.18 to $5.86 \mu \mathrm{g} / \mathrm{mL} .^{12.13}$ The common procedure for the analysis of DDT and its metabolites are $\mathrm{GC} / \mathrm{MS},{ }^{14.15}$ but the method requires extensive sample preparation and clean-up procedures. Immunoassay is suitable for environmental pollutants analysis due to its sensitivity, small sample volume requirements, cost-effectiveness, and rapidity.

This paper describes the competitive ELISA method for detemining the presence of DDT and its metabolites.

Fifteen hybridoma cell lines were obtained by cell fusion technology of myeloma cells and mice spleen cells immunized by conjugating $\mathrm{KLH}$ conjugate to three haptens (DDA. DDHP. DDCP). The antibodies were screened for their detection sensitivity for DDT and to test the influence of coating ligand. ${ }^{16.18}$ DDT and its metabolites were detected simultaneously using a matching pair of immunogen and antibody

\section{Experimental Section}

Reagents. Bovine serum albunin (BSA). ovalbumin (OVA) and keyhole limpet hemocyanine (KLH) were purchased from Pierce Chemical Co. (Rockford, IL., USA). $p, p^{\prime}-\mathrm{DDT}, p, p^{\prime}-\mathrm{DDE}$ and $p_{1} p^{\gamma}$-DDD were purchased from Chem Service Inc. (West Chester, PA. USA). $p, p^{\prime}$-DDA, $N$ hydroxysuccinimide (NHS), l-ethyl-3-(3-dimethylaminopropyl) carboimide hydrochloride (EDC) and organic solvents were purchased from Sigma-Aldrich Chemical Co. (St. Louis, MO., USA). Precoated preparative TLC plates (Art. 13895, PSC-Fertigplatten Kieselgel $60 \quad \mathrm{~F} 254$ for preparative chromatograpy, $20 \times 20 \mathrm{~cm}, 1 \mathrm{~mm}$ ) were purchased from Merck $\mathrm{Co}$. (Germany). ELISA substrate contained $70 \mathrm{mM}$ $o$-phenylenediamine (OPD) and $5.1 \mathrm{mM}$ hydrogen peroxide 
in $53 \mathrm{mM}$ sodium citrate buffer containing $10 \mathrm{mM}$ sodium hydrogen phosphate, $\mathrm{pH} 5.3$. PBST, $\mathrm{pH} 7.2$, contained 10 $\mathrm{mM}$ phosphate buffered saline (1'BS) with $0.05 \%$ J 'ween 20 . All chemicals used were of analytical grade, and the solutions were made with deionized water, using the Milli-Q water purification system (Millipore Inc., MA. USA). A microwell module (maxisorp) was purchased from Nunc (Denmark) and the optical density of the ELISA results was measured using an Emax precision microtiter plate reader (Molecular Devices Inc.. CA, USA).

Preparation of haptens, immunogens and coating ligands. Five haptens (Figure I) (DDA: 2,2-Bis(4-chlorophenyl)acetic acid, ${ }^{19}$ DDHP' 5,5-Bis(4-chlorophenyl)-5-hydroxypentanoic acid, ${ }^{20}$ DDCP: 5,5-Bis(4-chlorophenyl)-5-chloropentanoic acid. DDHH: 6,6-Bis(4-chlorophenyl)-6-hydroxyhexanoic acid, DDHHAP: 3-[6,6-Bis(4-chlorophenyl)-6-hydroxyhexanoylamino] propanoic acid), three immunogens (DDA-KLH, DDHP$\mathrm{KLH}, \mathrm{DDCP}-\mathrm{KLH}$ ) and ten coating ligands (combination of five haptens and two carrier protens: BSA, OVA) were prepared according to methods described in a previous paper: $^{21}$

Preparation of DDT monoclonal antibodies. DDT monoclonal antibody producing lybridoma cell lines were obtained by fusing myeloma and spleen cells of BALB/c mice immunized with one of the following inmunogens: DDA-KLH, DDHP-KLH or DDCP-KLH. Initial immunization was performed using an inmmunogen with complete freunds adjuvant emulsion (CFA), followed by twice boost injection with incomplete Freunds adjuvant enulsion (IFA). Fifteen DDT monoclonal antibodies were obtained through ELISA screening using various DDT-BSA derivatives as coating ligands.

A screening using various DDT-BSA derivatives as coating ligands.

Preparation of assay standards. PBS ( $10 \mathrm{mM}, \mathrm{pH} 7.2$ ) was used as the working buffer for all enzyme-linked immunosorbent assay (ELISA) experiments. A stock solution of $1 \mathrm{mg} / \mathrm{mL}$ DDl in DMSO was serially diluted in J'BS to $0.1 \mathrm{pg} / \mathrm{mL}$. The same method was used to prepare

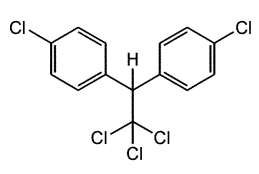

p,p'-DDT

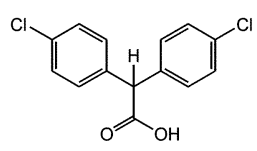

$p, p^{\prime}-\mathrm{DDA}$

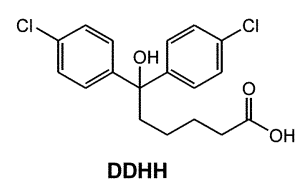

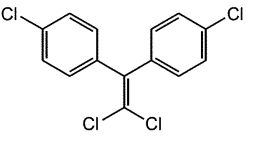

$p, p '-D D E$

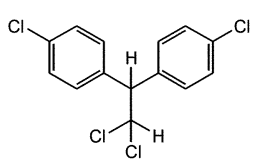

p,p'-DDD
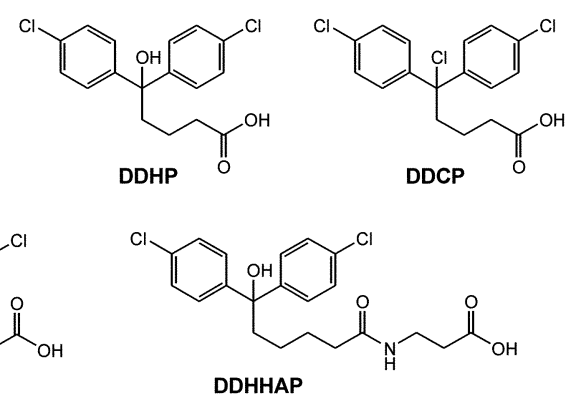

rigure 1. Chemical structures of IOI) analytes and prepared haplens standards of similar reactants at concentrations of $0.1,1,10$, $100,1000,10000$ and $100000 \mathrm{pg} / \mathrm{mL}$. Standards and similar reactants were stored at $4{ }^{\circ} \mathrm{C}$.

Assessment of titration levels of the antibodies by FLISA. A microtiter plate was coated with $50 \mu \mathrm{L}(10 \mu \mathrm{g} /$ $\mathrm{mL}$ ) of DDA-BSA coating ligand in $50 \mathrm{mM}$ carbonate buffer $\left(\mathrm{pH} \mathrm{9.6)}\right.$ for 12 hours at $4{ }^{\circ} \mathrm{C}$, and then washed three times with $200 \mu \mathrm{L}$ PBST. The wells were blocked using $150 \mu \mathrm{L}$ of $1 \% \mathrm{BSA}$ in PBS for 2 hours at room temperature and washed three times. The DDA-BSA coated microwells were incubated for 2 hours with $50 \mu \mathrm{L}$ of serially diluted $\mathrm{MAb}$ culture supernatant in $\mathrm{PBS}-1 \% \mathrm{BSA}$ solution at room temperature and washed. HRP-conjugated anti-mouse-IgG ( $200 \mu \mathrm{L}$ of $\mathrm{l} / 1000$ diluted solution) was added to each well and incubated for 2 hours at room temperature, and then washed five times with PBSI. After incubating for 10 minutes with $100 \mu \mathrm{L} \mathrm{Ol} \mathrm{D}$ substrate, the color reaction of the enzyme substrate was stopped with $50 \mu \mathrm{L}$ of $2 \mathrm{~N} \mathrm{H}_{2} \mathrm{SO}_{4}$. The optical density was read at $490 \mathrm{~nm}$. The titer level of antibodies was chosen by the level of antibody dilution to produce approximately $70 \%$ of maximum absorbance. The titer levels of antibodies for the other coating ligands were obtained in the same way. All assays were run in duplicate.

Dose-response curve for DDT analytes by ELISA. A dose-response curve for each DD' analyte ( $p, p^{*}$-DDT, DDA, $p, p^{*}$-DDE, $p, p^{\prime \prime}$-DDD) was established based on the assessment of the titer level of the antibody. The antibody coating step was the same as that in the antibody titration method. Jo construct a dose-response curve of DD [ analytes, $180 \mu \mathrm{l}$. fiee DDT analyte standard and $180 \mu \mathrm{L}$. antibody were mixed and pre-incubated for 2 hours at room temperature. Aliquots $(100 \mu \mathrm{l}$ ) $)$ of the resulting mixture were added to the hapten-protein coated wells. The remaining steps were then performed as described above. All assays were run in duplicate.

\section{Results and Discussion}

Five kinds of appropriate haptens resembling the chemical structure of DD' were synthesized for imınunodetection of DD' and its decomposition products. DD' derivatives (DDA, DDHP and DDCP') that have high similarity to DD'] haptens were coupled with keyhole limpet hemocyanin $(\mathrm{KLH})$ to use as an immunogen to produce antibodies. The bovine serum albumin (BSA) conjugates of these derivatives were prepared as a coating ligand for the monoclonal antibody screening. Fifteen monoclonal antibody clones were screened using these probes. Five kinds of synthetic haptens (DDA, DDHP, DDCP, DDHH and DDHHAl') were coupled with carrier proteins, BSA or OVA, for use as a coating ligand. The monoclonal antibodies (MAb) were characterized for their affinities and specificities to DD'] analytes with the ten coating ligands above. The absorbance values in Table 1 show the degree of binding ability between the antibodies and coating ligands under the same reaction procedures. The titer level of each antibody was determined by competitive ELISA, using coating ligands. The antibody 
Table 1. Elfect of coating ligand on the titration curves

\begin{tabular}{|c|c|c|c|c|c|c|c|c|c|c|c|}
\hline \multirow{3}{*}{ Immunogen } & \multirow{3}{*}{$\begin{array}{l}\text { WAb } \\
\text { clone }\end{array}$} & \multicolumn{10}{|c|}{ Iiter level } \\
\hline & & \multicolumn{5}{|c|}{ BSA-coating ligand } & \multicolumn{5}{|c|}{ OVA-coating ligand } \\
\hline & & $\begin{array}{l}\text { DDA- } \\
\text { BSA }\end{array}$ & $\begin{array}{l}\text { DDHP- } \\
\text { BSA }\end{array}$ & $\begin{array}{l}\text { DDCP- } \\
\text { BSA }\end{array}$ & $\begin{array}{c}\text { DDHH- } \\
\text { BSA }\end{array}$ & $\begin{array}{c}\text { DDHHAP- } \\
\text { BSA }\end{array}$ & $\begin{array}{l}\text { DDA- } \\
\text { OVA }\end{array}$ & $\begin{array}{c}\text { DDHP- } \\
\text { OVA }\end{array}$ & $\begin{array}{c}\text { DDCP- } \\
\text { OVA }\end{array}$ & $\begin{array}{c}\text { DDHH- } \\
\text { OVA }\end{array}$ & $\begin{array}{c}\mathrm{DDHH} \wedge \mathrm{P}- \\
\text { OVA }\end{array}$ \\
\hline \multirow{5}{*}{$\mathrm{DD} \wedge-\mathrm{KLH}$} & {$[\mathrm{A}]$} & 3.22 & 3.11 & 3.18 & 2.97 & 2.97 & 0.44 & 0.31 & 0.30 & 0.30 & 0.23 \\
\hline & $\mathrm{I} \wedge 2$ & 0.78 & 0.57 & 0.44 & 0.33 & 0.44 & 0.86 & 2.24 & 1.00 & 0.99 & 1.06 \\
\hline & $\mathrm{I} / \mathrm{3}$ & 0.07 & 0.08 & 0.07 & 0.19 & 0.13 & 0.66 & 0.78 & 0.57 & 0.50 & 0.53 \\
\hline & $\mathrm{I} \Lambda 4$ & 0.08 & 0.08 & 0.06 & 0.20 & 0.10 & 0.39 & 0.47 & 0.37 & 0.41 & 0.48 \\
\hline & 1136 & 0.18 & 0.16 & 0.15 & 0.24 & 0.20 & 0.55 & 0.69 & 0.58 & 0.62 & 0.64 \\
\hline \multirow{5}{*}{ DDHP-KLH } & $2 \Lambda 1$ & 0.36 & 0.22 & 0.09 & 0.32 & 0.19 & 0.14 & 0.11 & 0.12 & 0.12 & 0.23 \\
\hline & $2 \wedge 2$ & 0.15 & 0.15 & 0.09 & 0.29 & 0.19 & 0.14 & 0.10 & 0.11 & 0.15 & 0.26 \\
\hline & $2 \Lambda 6$ & 0.33 & 0.17 & 0.09 & 0.53 & 0.24 & 0.14 & 0.17 & 0.21 & 0.13 & 0.30 \\
\hline & $2|3|$ & 0.31 & 0.43 & 0.13 & 0.24 & 0,26 & 0.13 & 0.14 & 0.11 & 0.22 & 0.60 \\
\hline & 2133 & 0.08 & 0.09 & 0.09 & 0.34 & 0.43 & 0.60 & 0.54 & 0.46 & 0.43 & 1.01 \\
\hline \multirow{5}{*}{ IDI)(P-K1.II } & $3 \wedge 1$ & 3.42 & 3.39 & 3.38 & 3.36 & 3,35 & 3.16 & 3.23 & 3.13 & 3.17 & 3.26 \\
\hline & $3 \wedge 2$ & 0.64 & 0.56 & 0.78 & 0.61 & 0.56 & 1.60 & 1.95 & 1.86 & 1.82 & 1.88 \\
\hline & $3 \wedge 3$ & 0.22 & 0.15 & 0.11 & 0.14 & 0.13 & 0.59 & 0.58 & 0.48 & 0.66 & 0.59 \\
\hline & $3 \wedge 4$ & 0.51 & 0.37 & 0.15 & 0.16 & 0.18 & 0.59 & 0.61 & 0.51 & 0.53 & 0.55 \\
\hline & $3 \wedge 5$ & 1.39 & 1.07 & 1.03 & 1.52 & 0.24 & 0.91 & 1.00 & 0.73 & 0.71 & 0.69 \\
\hline
\end{tabular}

"The titer level was determined by the value of antibody dilution fold on the $70 \%$ of maximum absorthance.

concentration that showed $70 \%$ of maximum binding response (absorbance at $490 \mathrm{~nm}$ ) was determined as the titer level. We observed that the affinities varied depending on the coating ligands that were derivatized to different structures and conjugated with different carrier proteins. MAb $1 \mathrm{Al}$ and 3 A5 showed higher binding affinity on the BSA coating ligands than on the OVA coating ligand. They were obtained from the DDA-KLH and DDCP-KLH immunogens, respectively. Most of the MAbs obtained from the DDHP$\mathrm{KLH}$ immunogen showed low binding affinity with the exception of the pairs of $\mathrm{MAb} 2 \mathrm{B3}$ and OVA coating ligands. $1 \mathrm{~A} 2$ and $1 \mathrm{~B} 6$ antibodies showed good affinity for OVA coating ligands. Despite its strong affinity for all coating ligands. MAb 3Al, which was produced from DDCP-KLH immunogen, could not be used to obtain good competitive curves for DDI analytes. When the antibody has a very strong affinity for the coating ligand, good assay sensitivity cannot be obtained because free analytes cannot easily bind to the antibody in competition with the coating ligand. Colbert et al. ${ }^{22}$ also reported that increased sensitivity was achieved by reducing the antibody affinity of the tracer.

To screen a matching pair of antibody and coating ligand for the simultaneous detection of DDI and its related compounds (DDT, DDA. DDE. DDD), each antibody was investigated for the displacement of free ligand, using selected coating ligands through the method of affinity screening. Selected were four matching pairs of antibody and coating ligand that showed reactivities to DDT, DDA, DDE and DDD. Figure 2 shows the results for displacement responses of DDI analytes, using a selected pair of antibody and coating ligand. They were $\mathrm{MAb} 1 \mathrm{~A} l$ with coating ligand of DDHHAP-BSA, MAb 1 A3 with DDA-OVA or DDHPOVA and MAb IA4 with DDHP-OVA. Table 2 shows the relative reactivity and sensitivity of DDT analytes using a
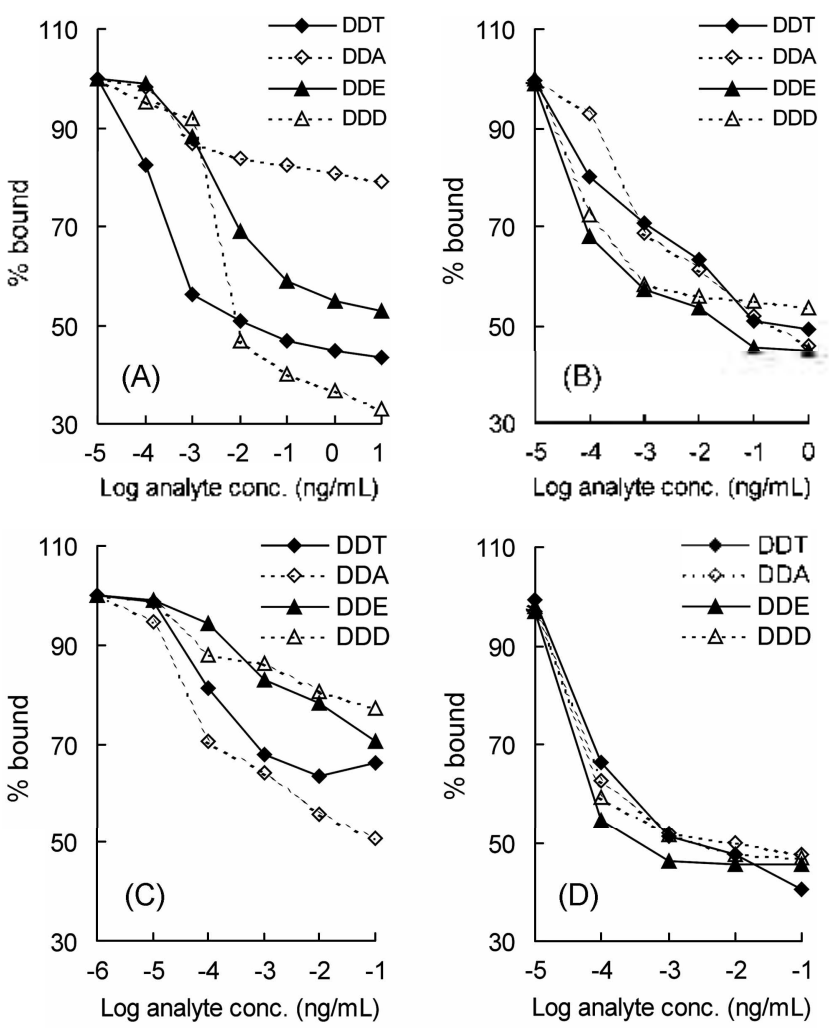

Figure 2. Dose-response curves of DD' analyles. The MAbs $(50$ $\mu \mathrm{L}$ of titcr level of each antibody) and the coating ligand ( $50 \mu \mathrm{L}$ of $10 \mu \mathrm{g} / \mathrm{ml} \mathrm{l}$ ) that were used for the dose-response curve of [DDT analytes: $(A) \mathrm{MAb} I B I) A 1 / 1$ with I)IOHIIAP-BSSA coating ligand. (B) MAb DDA IA3 wilh DDA-OVA coating ligand. DDA $1 \mathrm{~A} 4$ with DDHP-OVA coating ligand.

selected pair of antibody and coating ligand. The detection limit of each analyte was obtained by the dose-response curve at the optimum condition of the respective pair of 
Table 2. Relative reactivity of DDT analy tes with a matching pair of antibody and coating ligand

\begin{tabular}{|c|c|c|c|c|}
\hline Antibody & $\begin{array}{l}\text { Coating } \\
\text { ligand }\end{array}$ & $\begin{array}{c}\text { DDT } \\
\text { antaly tes }\end{array}$ & $\begin{array}{c}\text { Relative } \\
\text { reactivity }(\%)\end{array}$ & $\begin{array}{l}\text { Sensitivity } \\
(p \mathrm{~g} / \mathrm{mL})\end{array}$ \\
\hline \multirow{4}{*}{$\begin{array}{l}\mathrm{DDA} \\
\mathrm{lAl}\end{array}$} & \multirow{4}{*}{$\begin{array}{l}\text { DDHHAP- } \\
\text { BSA }\end{array}$} & $p, p-\mathrm{DDT}$ & 100 & 0.12 \\
\hline & & $p \cdot p-\mathrm{DDA}$ & 4.2 & - \\
\hline & & $p, p-\mathrm{DDE}$ & 3.3 & 5.34 \\
\hline & & $p \cdot p^{i}-\mathrm{DDD}$ & 6.0 & 1.82 \\
\hline \multirow{8}{*}{$\begin{array}{l}\mathrm{DDA} \\
\mathrm{lA} \hat{3}\end{array}$} & \multirow{4}{*}{$\begin{array}{l}\text { DDA- } \\
\text { OVA }\end{array}$} & $p, p^{\prime}$-DDT & 100 & 0.10 \\
\hline & & $p, p^{-D D A}$ & 3.3 & 0.34 \\
\hline & & $p, p^{\prime}-\mathrm{DDE}$ & 201 & 0.04 \\
\hline & & $p, p^{\prime}$-DDD & 172 & 0.05 \\
\hline & \multirow{4}{*}{$\begin{array}{l}\text { DDHP- } \\
\text { OVA }\end{array}$} & $p, p^{\prime}-\mathrm{DDT}$ & 100 & 0.70 \\
\hline & & $p, p^{\prime}-\mathrm{DDA}$ & 122 & 0.11 \\
\hline & & $p, p-\mathrm{DDE}$ & 146 & 475 \\
\hline & & $p \cdot p^{\prime}$-DDD & 129 & 9378 \\
\hline \multirow{4}{*}{$\begin{array}{l}\mathrm{DDA} \\
\mathrm{lA} 4\end{array}$} & \multirow{4}{*}{$\begin{array}{l}\text { DDHP- } \\
\text { OVA }\end{array}$} & $p \cdot p-\mathrm{DDT}$ & 100 & 0.08 \\
\hline & & $p, p^{-D D A}$ & 107 & 0.06 \\
\hline & & $p \cdot p-\mathrm{DDE}$ & 134 & 0.04 \\
\hline & & $p, p-\mathrm{DDD}$ & 121 & 0.05 \\
\hline
\end{tabular}

"ao. Relative reactivity defined as ${ }^{\circ} 0$ ratio of concentration for $70^{\circ} \circ$ displacement by DDT concentration: $70^{\circ} \mathrm{n}$ displacement by other analyte. "Sensitivity detined as the concentration of DDT analytes that yielded $80^{\circ}$. of the maximum response from zero concentration on the dose-response curve.

antibody and coating ligand. The relative reactivities of DDT analy tes were compared with $70 \%$ inhibition concentration of DDT. Sensitivity was defined as the concentration of DDT analytes that yielded $80 \%$ of the maximum response from zero concentration on the dose-response curve. The relative reactivity values of DDT analytes when using the pair of MAb IAl and DDHHAP-BSA were calculated as $100,4.2,3.3,6.0 \%$. With MAb IA3 and DDA-OVA. they were 100. 3.3. 201, 172\%: with MAb 1A3 and DDHP-OVA. they were $100,122,146,129 \%$, and with MAb $1 \mathrm{~A} 4$ and DDHP-OVA. they were 100, 107. 134. 121\% (Table 2). MAb IA4 and DDHP-OVA coating ligand exhibited high sensitivity values for the DDT analytes (DDT. DDA. DDE and DDD), but the combination of MAb IA3 and DDAOVA exhibited the best response. covering a wide range of DDT levels.

The results indicate that DDT was the most responsive to the pair of $1 \mathrm{Al}$ and DDHHAP-BSA: DDE to the pairs of $1 \mathrm{~A} 3$ and DDA-OVA and 1A4 and DDHP-OVA: and DDA to the pair of $1 \mathrm{~A} 3$ and DDHP-OVA. From these observations. we conclude that the length of spacer that is attached for coupling of carrier protein in immunogen and coating ligand could significantly influence the immunoreactivity of an indirect ELISA by affecting the antibody affinity and doseresponse immunoreaction.

In conclusion. it is important to screen a best matching pair of antibody and coating ligand for the immunoreactions of affinity and displacement with DDT analytes. DDA-KLH immunogen and DDA-OVA coating ligand were the best combination at a wide range of DDT analytes.

Acknowledgment. This investigation was supported by a fund of the National Research Laboratory Program (No. 2000-N-NL-01-C-045), Ministry of Science and Technology, Republic of Korea.

\section{References}

1. Rochling. H. Ih Chemistry of Plant Protection and lector Contol Agents: Wegler. R.. Ed.: Springer-Verlag: Berlin1. 1970: Vol. 1. p 121 .

2. World Health Organization. En miwnmental Healh Criteria (EHC) 83: DDT and Its Derwatives-Enironmental Aspects: WHO: Geneva 1989

3. Korte. F.. Ed.: Textbook of Ecological Chemisny Basics and Concepts for the Ecological Assessment of Chenticat. Thiemverlag: Stuttgart. 1992

4. Agarwal. H. C.: Singh. D. K.: Shama. V. B. J. Enninon. Sci. Healh 1994. 29.87.

5. Guenzi, W. D.: Beard. W. E. Science 1967, 156, 1116.

6. Ramachandran, M.: Zaidi. S. S. A.; Banerjee, B. D.: Hussain. Q. Z. Indian J. Med. Res 1984b. 80.483 .

7. Voldner. E. C.: Li. Y. F. Sci. Total Eminon. 1995. 160.161.201.

8. Mitra. J.: Raghu. K. Bull. Ention. Contan. Toxicol 1998. 60. 852.

9. Phoung. H. K.: Son. C. P. N.; Sauvain, J.-J.; Taradellas, J. Bull. Eniron. Contam. Toxicol. 1998. 60, 347.

10. Pardio. V. T. et al. Bull. Enimon. Contan. Toxicol 1998. 60. 852.

11. WHO. LDT and Its Derivatives: Environmental Health Criteria 9 World Health Organization: Geneva. 1979.

12. Watts. R. R. Mamal of Analytical Qualin Control of Pesticides and Related Compounds in Homans and Enimomental Samples, Environmental Protection Agency: Research Triangle Park. NC. U.S. 1981: p 319

13. Ramachandran. M.: Baneriee. B. D.: Gulati. M.: Grover. A.: Zaidi. S. S. A.: Hussain. Q. Z. Indian J. 1 fed. Res. 1984a. 80.590.

14. Buser. H. R.: Muller. M. D. Anal. Chem. 1995. 67.2691

15. Chuang. J. C. Hart. K Chang, J. S.; Boman, L. E; Van Emon, J. M; Reed. A. W. Anal Chim Acta 2001. $44,87$.

16. Harrison. R. O.: Goodrow: M. H.: Gee. S. J.: Hammock. B. D. Hapten Sinthesis for Pesticide Immmoassay Developntent. In Inunuoassays for Trace Chemical Andysis: Vanderlaat1. M.. Stanker, L. K.. Wathins, B. E.. Roberts, D. W. Eds.; ACS Symposium Series 451; American Chemical Society: Washington. DC. 1990: p 14.

17. Abad. A.: Manclus. I. T.: Mojarrad. F.: Mercader. J. V: Miranda. M. A.: Primo. T.: Guardiola. V: Montoya. A. J.Agric. Food Chent. 1997.45 .3694 .

18. Goodrow M. H.: Harrison. R. O; Hammock, B. D. J. Agric. Food Chem. $1990,38,990$.

19. Grummitt. O.: Buck. A.: Egan, R. Organic Smmesis 1946, 26. 21.

20. Langon. T. T.: Van Vunakis. H. Methods Enzmntol. 1982. 84. 628.

21. Hong. .T. Y.: Kiml. Т.-H.: Choi. M. I. Bull. Korean Chem. Soc. 2002. 23,1413 .

22. Colbert, D. L.: Eremin, S. A.: Landon. J. J. Inmunological Methods 1991. 1+0.227. 